\title{
Research on Impact of Different Environmental Regulation Tools on Energy Efficiency in China
}

\author{
$\operatorname{Ran} \mathrm{Li}^{1,2}$, Tao Sun ${ }^{1 *}$ \\ ${ }^{1}$ College of Economics and Management, Nanjing University of Aeronautics and Astronautics, Nanjing, Jiangsu, China, \\ No. 29 Jiangjun Avenue, Jiangning District, Nanjing,China \\ ${ }^{2}$ Jincheng College, Nanjing University of Aeronautics and Astronautics, Nanjing, Jiangsu, China, \\ 88 Hangjin Avenue, Lukou Street, Jiangning District, Nanjing,China
}

Received: 20 December 2019

Accepted: 14 April 2020

\begin{abstract}
This paper uses the super-efficiency DEA model to study the super-efficiency energy efficiency values of 30 provinces in China from 2006 to 2018, compares the differences between different regions, and verifies the impact of different environmental regulatory tools on energy efficiency. The results show that the regions with the highest energy efficiency in China's provinces are, in order, the eastern region, the central region, and the western region. At the same time, the impact of different environmental regulatory tools on energy efficiency is quite different. The number of environmental administrative penalties has a negative impact on China's energy efficiency, that is, increased number of environmental administrative penalties will reduce China's energy efficiency; market-encouraging environmental regulations tools impact on China's energy efficiency show a positive correlation, which means that market-encouraging environmental regulation tools are conducive to achieving a win-win goal of environmental regulation and energy efficiency in China. The voluntary environmental regulation tool has a negative correlation with energy efficiency, but it is not statistically significant, indicating that it is not the main factor affecting energy efficiency. In terms of other influencing variables, the level of economic development and technological progress are positively related to energy efficiency. The proportion of the secondary industry in regional GDP is positively related to energy efficiency, the relationship between energy consumption structure and energy efficiency is negative correlation, the degree of opening to the outside world has a negative correlation to China's energy efficiency.
\end{abstract}

Keywords: system GMM model, energy efficiency, sustainable development, environmental regulation

*e-mail: taosnuaa@163.com 


\section{Introduction}

Energy is an indispensable factor of production in the process of people's production and life. It plays a vital role in the high-quality development of the regional economy. China has abundant energy resources, a vast area, and a large population. The average level and external dependence have increased year by year [1]. With the continuous progress of industrialization and urbanization, while China has achieved great economic achievements, energy consumption has also increased rapidly. According to the BP World Statistical Yearbook 2017, China accounted for 23\% of global energy consumption and $27 \%$ of global energy consumption growth in 2016 [2]. China's economic growth is in the process of continuously accelerating the development of industrialization and urbanization. With the continuous increase of China's population, energy resources will undoubtedly become an important pillar to ensure the sustainable and healthy development of China's society and economy. Constantly abundant and long-term stable energy input is not only related to national energy security and environmental issues, but also to the stable and sustainable development of the economy.

Since the reform and opening up, with the rapid progress of China's industrialization and urbanization, while China's economy has maintained rapid growth, the deterioration of the ecological environment caused by excessive energy consumption is being exposed sharply in China, and environmental protection has become an important livelihood issue. The carrying capacity of resources and the environment in most parts of China has reached or approached the upper limit. Various environmental pollution problems caused by excessive energy consumption and low energy efficiency have emerged endlessly, such as the greenhouse effect, haze days, and large-scale pollution of groundwater. The sustainable development of the future economy poses severe challenges. The contradiction between environmental protection and economic growth constitutes a key constraint for the construction of a harmonious society. In order to break through the severe energy and environmental constraints and achieve sustainable economic and social development, we must work to improve energy efficiency and promote the transformation of the Chinese economy into a green growth mode with low energy consumption, low emissions, and high output [3-5]. At present, it is urgent to improve the quality and efficiency of economic development and promote energy conservation and emission reduction. Energy efficiency as one of the important indicators to describe the degree of coordinated development of energy consumption and economy, can intuitively reflect the relationship between multiple inputs such as energy and labor capital and economic output, and is also one of the criteria for measuring whether the economy can achieve sustainable development [6]. And while environmental regulation is a core tool for reducing energy use and controlling pollution emissions, Porter (1991) points out that appropriate government environmental regulations can help enterprises to carry out innovative activities, improve energy efficiency and corporate competitiveness, and achieve environmental protection and improvement a win-win situation for energy efficiency [7]. Environmental regulation can alleviate the pressure on resources and the environment by saving energy, and on the other hand, it can increase the cost of pollutants discharged by enterprises through strict control of pollution emissions, prompting enterprises to adjust production methods and improve resource utilization efficiency. But there are many environmental regulation tools. How does the implementation of different environmental regulations affect energy efficiency? Based on the measurement of energy efficiency in various regions of China, this paper divides environmental regulatory tools into three types: command and control, market encouragement, and voluntary. The system GMM model is used to verify the impact of different environmental regulatory tools on China's energy efficiency. The impact of other factors on the energy efficiency of various provinces is of great practical significance for China to accelerate the implementation of the concept of green development, to achieve a clean, low-carbon, and efficient sustainable development path, and to improve the quality and efficiency of economic growth.

\section{Literature Review}

Energy is an indispensable input element for economic growth, and it has an important impact on economic development. The impact of environmental regulations on energy efficiency has become a hotspot in the relationship between politics and academia. At present, there are three main views: (1) Government environmental regulations will increase the production costs of enterprises, leading to a reduction in enterprise production performance, and have a suppressive effect on the improvement of energy efficiency [8-9]. Jorgenson and Wilcoxen (1997) shown that environmental regulation will increase costs or reduce investment, and prove that environmental regulation will reduce the growth rate of the US economy during the study period [10]. Li Weina and Jin Xiaoyu (2011) calculated the energy efficiency of the manufacturing industry considering undesired output conditions, and measured the intensity of environmental regulations with desulfurization facilities, and concluded that environmental regulations did not achieve the effect of improving energy efficiency [11]. You Jihong and Gao Zhigang (2013) verified from two perspectives of single factor energy efficiency and total factor energy efficiency that government environmental regulations will inhibit the improvement of energy efficiency [12]. Chen Ling and Zhao Guochun (2014) selected Xinjiang data from 2003 to 2010 and studied it using 
the SFA method. It was found that the Xinjiang government's investment in controlling environmental pollution has improved energy inefficiency, that is, environmental regulations have produced energy inefficiency [13].

(2) Appropriate government environmental regulations will encourage enterprises to carry out technological reforms and innovations, thereby improving energy efficiency, offsetting the increased production costs due to government environmental regulations, and achieving a win-win situation in which economic growth and environmental protection coexist, which is the "Porter hypothesis". Wan Lunlai and Tong Mengyi (2010) empirically analyzed the relationship between environmental regulation, industrial structure and technological innovation and energy intensity, and found that environmental regulation can effectively promote the improvement of energy efficiency [14]. Li Bin and Chen Chongnuo (2016) research results show that economic incentives and voluntary awareness of environmental regulations are significantly related to industrial energy efficiency, and corresponding environmental regulations can promote industrial energy efficiency improvement [15]. Fan Mengqi (2015) calculated the total factor energy efficiency value of various provinces in China from 2002 to 2012 using the DEA method, and used Tobit panel regression to conclude that environmental regulations can promote the improvement of total factor energy efficiency [16]. Bai Xuejie and Song Ying (2009) found that environmental regulation has a positive incentive effect, which can not only improve energy efficiency, but also promote technological innovation [17]; the "Porter Hypothesis" proposed by Porter and Linde (1995) believes that it is strict and appropriate The designed environmental regulation can stimulate the innovation activities of enterprises, and the resulting innovation "compensation effect" can partially or even completely offset the cost of environmental regulation, which is conducive to the improvement of productivity [18].

(3) The relationship between environmental regulation and energy efficiency is not a nonlinear relationship, but depends on whether the "innovation compensation" effect of environmental regulation on industrial performance can offset the "compliance cost" effect. Gaoshan (2012) studied the impact of environmental regulation on energy efficiency in high-energy-consuming industries through direct and indirect mechanisms, and concluded that the impact of environmental regulation on energy efficiency was an inverted "U" [19]. Gao Zhigang and You Jihong (2015) conducted research using data from China's interprovincial panels from 2000 to 2012, and concluded that environmental regulation can promote energy efficiency improvement through an inverse mechanism. There is a "U" relationship between of them [20]. Chen Demin and Zhang Rui (2012) found that different environmental regulatory tools have different effects [21]. Wang Teng et al. (2017) found that when the intensity of environmental regulation is less than 0.0002 , the impact of environmental regulation on total factor energy efficiency and technological level is positive, and the Porter hypothesis is established at this time; when the intensity of environmental regulation exceeds 0.0002, environmental regulation had a negative impact on total factor energy efficiency and technological level. At this time, the Porter hypothesis was not valid [22]. Xiong Huanhuan and Deng Wentao (2017) found that environmental regulation promotes the agglomeration of heavily polluting industries and is not conducive to moderately polluting industries. The increase in the degree of agglomeration has no significant impact on the lightly polluted industry [23].

By combing the existing relevant research literature, we can see that the above research has reached some very valuable conclusions, which has important reference significance for China to formulate reasonable energy and environmental policies. However, it is not difficult to find that these research results still have certain shortcomings, mainly in the following aspects: First, most sources ignore the unintended output of environmental pollution when constructing econometric models to calculate energy efficiency, leading to the model. The estimated parameter results are biased, so the calculated energy efficiency value is not accurate, and there is a large gap from the actual situation. Second, there are few existing studies on the classification of environmental regulations, which cannot reflect the impact of different environmental regulations on energy efficiency. This paper considers the mechanism and direction of different environmental regulations on energy efficiency, and examines the effects of environmental regulations.

\section{Methods}

\section{Super Efficiency DEA}

Regional ecological efficiency evaluation is a multiinput single-output efficiency measurement problem. This paper chooses to use the super-efficiency DEA model to solve this problem. The traditional DEA model calculates the level of each DMU relative to the efficiency frontier by constructing a relatively effective frontier that includes several decision units (DMUs), and the relative value reflects the efficiency level of the DMU. When the efficiency value is greater than 1 , the DEA is valid; if it is less than 1, the DEA is invalid. The key of the super-efficiency DEA model is to be able to separate the effective decision-making units based on the traditional DEA model and calculate the proportion of the output that the DMU can reduce based on the constant technical efficiency, thereby comparing the efficiency between DMUs greater than 1. The super-efficiency DEA model can be expressed as follows: 


$$
\left\{\begin{array}{l}
\min \left[\theta-\varepsilon\left(\sum_{i=1}^{m} s_{i}^{-}+\sum_{r=1}^{s} s_{r}^{+}\right)\right] \\
\sum_{\substack{j=1 \\
j \neq k}}^{n} \lambda_{j} X_{i j}+S_{i}^{-} \leq \theta X_{0} \\
\sum_{\substack{j=1 \\
j \neq k}}^{n} \lambda_{j} Y_{j}-S_{r}^{+}=Y_{0} \\
\lambda_{j} \geq 0, \mathrm{j}=1,2, \ldots, \mathrm{n}, \quad S_{r}^{+} \geq 0 ; S_{i}^{-} \geq 0
\end{array}\right.
$$

In the method: $\varepsilon$ is a non-Archimedean infinitesimal quantity, $\lambda \mathrm{j}$ is the weight relative to the jth decision unit of the current decision unit, $\mathrm{X}_{0}$ and $\mathrm{Y}_{0}$ are the input and output values of the current decision unit, and $\theta$ is the efficiency value of the decision unit, $\mathrm{X}_{\mathrm{ij}}$ and $\mathrm{Y}_{\mathrm{j}}$ are the $\mathrm{i}$-th input value of the $\mathrm{j}$-th decision unit and the output value of the j-th decision unit, and $S_{i}^{-}$and $S_{r}^{+}$are the relaxation variables of the $\mathrm{i}$-th input and the $\mathrm{r}$-th output, respectively.

\section{System GMM Model}

In order to prevent excessive heterogeneity of sample individuals and endogenous variables, we use the first-order differential generalized moment estimation (GMM) method proposed by Arella- no \& Bond. Compared with the traditional OLS estimation method, WLS estimation method, instrumental variable method and maximum likelihood estimation method, the GMM estimation method allows heteroscedasticity and sequence correlation for random error terms, and the GMM parameter estimates are more effective than other methods. The model is constructed as follows:

$$
\mathrm{y}_{\mathrm{it}}=\alpha y_{i t-1}+\beta X_{i t}+\mu_{i}+\varepsilon_{i t}
$$

...where $\mathrm{y}_{\mathrm{it}}$ is the explanatory variable, $\mathrm{X}_{\mathrm{it}}$ is the explanatory variable, $\mu_{i t}$ is the regional effect, and $\varepsilon_{t}$ is the residual of the model. In order to solve the possible individual fixed effects, Arellano-Bond used the GMM method to perform first-order difference processing on the formula, and obtained:

$$
\Delta y_{i t}=\alpha \Delta y_{i t-1}+\beta \Delta X_{i t}+\Delta \mathcal{E}_{i t}
$$

It can be seen from the formula that the model after differential processing solves the individual fixed effects. Although the system GMM method does not need to consider the stability of the data, there is a two-way causal relationship between the variables, also called endogenousness. In order to solve this endogenousness, this article uses the Sargan test and the Arellano-Bond test to verify the model and variables Scientific.

\section{Results}

\section{Calculation Results of China’s Regional Energy Efficiency}

\section{Variable Selection}

Considering the completeness and availability of the data, this paper takes the capital stock, labor force, and energy input of 30 provinces, municipalities, and autonomous regions (excluding Tibet as a result of the lack of data) in 2006-2018. The GDP and industrial exhaust emissions of each province and city are used as output indicators to evaluate the energy efficiency of each province, city, and autonomous region:

The specific index selection is shown in Table 1.

\section{Indicator Interpretation and Data Processing}

(1) Energy: The energy consumption is expressed by the total energy consumption of the western provinces (autonomous regions and municipalities) over the years. In real life, there are many types of energy consumption in various regions, and the units are not unified. In order to compare the energy consumption of various regions more conveniently, the primary primary energy sources such as coal, oil and natural gas in various regions are usually statistically compared [24-25]. The equivalent consumption is converted into a unified standard coal; the unit is 10,000 tons of standard coal. Data on energy consumption comes from the China Energy Statistics Yearbook 2006-2018.

(2) Labor: Labor input includes two evaluation indicators, labor quantity and labor quality. Considering the availability of data, only the labor quantity index is

Table 1. Index selection.

\begin{tabular}{|c|c|c|}
\hline Index & Secondary indicators & Tertiary indicators \\
\hline \multirow{3}{*}{ Input } & Labor force & Employment in the year (10,000 people) \\
\cline { 2 - 3 } & Capital & Capital stock (ten thousand yuan) \\
\cline { 2 - 3 } & Energy & $\begin{array}{c}\text { Total energy consumption by province } \\
(10,000 \text { tons of standard coal) }\end{array}$ \\
\hline \multirow{2}{*}{ Output } & Expected output & Real GDP (100 million yuan) \\
\cline { 2 - 3 } & Unexpected output & Exhaust emissions \\
\hline
\end{tabular}


used here. The number of laborers is the average of the number of employed persons at the end of the previous year and the number of employed persons at the end of the year [26-27].

(3) Capital: The capital stock is used as an evaluation index of capital investment. To eliminate the influence of price factors, the actual capital stock value with a constant price in 2006 is used. The current common method for estimating the capital stock is the perpetual inventory method [28]:

$$
K_{t}=K_{t-1}\left(1-\delta_{t}\right)+I_{t}
$$

Among them, $K_{\mathrm{t}}$ is the capital stock in year $\mathrm{t}, K_{t-1}$ is the capital stock in year $\mathrm{t}-1, \delta t$ is the economic depreciation rate in year $t, I t$ is the new investment in year $\mathrm{t}$.

(4) Expected output: The actual GDP is selected as the desired output variable of each province (autonomous region, municipality) in the country [29]. In order to avoid the influence of price changes, the GDP deflator is used to convert the original data at a comparable price into the actual GDP with a base period of 2006. All the raw data of GDP are derived from the statistical yearbooks of western provinces and municipalities from 2006 to 2018.

(5) Unexpected output

Since the pollution caused by energy consumption is mainly air pollution [30-31], and the input-output indicators required by the DEA model should not be too much, this article combines the actual conditions in China and finally selects the exhaust gas emissions as undesired output Indicators, and specific data on exhaust emissions by region are from the 2006-2018 China Environmental Yearbook.

\section{Calculation Results of China's Regional Energy Efficiency}

Using DEAP 2.1 software, the determined input indicators and output indicators are substituted into the model, and the calculation results are shown in Table 2.

As can be seen from the table above, the region with the highest energy efficiency from 2006 to 2018 is the eastern region, with an average efficiency value of 0.763 . The average energy efficiency of the provinces in the eastern region is above 0.7. The second average value of energy efficiency is the central region. It is 0.453. During the sample period, the overall trend is slowly increasing, and gradually stabilizes above 0.5 from the initial 0.406 . The change trend is the same as that of the national average energy efficiency value. The lowest energy efficiency value is in the western region of China. Its efficiency value has been around 0.4 , but it can also be found that the average energy efficiency in the central and western regions is very close. This is inconsistent with the research results of many authors. Some previous studies did not analyze environmental factors as the output of energy utilization, which led to deviations in the measurement results of energy efficiency, which is also one of the innovations in this paper.

\section{System GMM Model Regression Analysis}

\section{Variable Selection}

(1) Explained variable: China's regional energy efficiency. The value of the comprehensive energy efficiency including environmental constraints calculated using the data envelopment analysis method described above is recorded as EE.

(2) Explanatory variables

The effect of environmental regulation is not only determined by the intensity of environmental regulation. It is also affected by environmental regulation methods. The effects produced by different environmental regulation methods are different. Therefore, in addition to studying the impact of environmental regulation intensity on energy efficiency, It is also necessary for regulatory tools to specifically analyze differences in their effects on energy efficiency. Environmental regulation tools are divided into three types: command control type, market encouragement type and voluntary type. Command type environmental regulation tools generally set standards, and require that the objects to be regulated must meet the set standards. Pollutants exceeding the set standards are not allowed to be discharged, or take coercive measures to punish them. Market-inspired environmental regulation tools are mainly used to achieve environmental protection purposes through the implementation of sewage charges and environmental taxes and fees. Among them, sewage charges are an earlier and longer-term market-based environmental regulatory tool in China. The purpose of collecting sewage charges is to form a constraint on the enterprises that discharge sewage and urge them to adjust and optimize their production and operation strategies. Develop new technologies to achieve the full use of resources, reduce emissions of pollutants and improve the ecological environment. Voluntary environmental regulation is to mobilize the public's enthusiasm to participate in environmental protection, and to form a social atmosphere of environmental protection for all people. There is no doubt that this method can achieve better results in improving environmental quality. In the long-term development in the future, attention should be paid to the use of this environmental regulation tool and its continuous improvement and development.

The command-and-control environmental regulation tool is the earliest environmental policy tool in China. It mainly manifests in the government setting some standards or regulations and requiring enterprises to implement them. If they fail to meet the standards, they will be subject to economic or administrative penalties. Based on data availability and continuity considerations, this article selects the number of environmental 
Table 2. Measurement results.

\begin{tabular}{|c|c|c|c|c|c|c|c|c|c|c|c|c|c|c|c|}
\hline & Region & 2006 & 2007 & 2008 & 2009 & 2010 & 2011 & 2012 & 2013 & 2014 & 2015 & 2016 & 2017 & 2018 & Mean \\
\hline \multirow{11}{*}{ Eastern } & Beijing & 0.901 & 0.923 & 0.977 & 0.921 & 0.954 & 0.967 & 0.979 & 0.992 & 1.006 & 1.133 & 1.148 & 1.397 & 1.438 & 1.057 \\
\hline & Tianjin & 0.612 & 0.615 & 0.628 & 0.616 & 0.629 & 0.633 & 0.648 & 0.658 & 0.676 & 0.689 & 0.699 & 0.707 & 0.733 & 0.657 \\
\hline & Hebei & 0.379 & 0.381 & 0.399 & 0.389 & 0.408 & 0.418 & 0.429 & 0.437 & 0.449 & 0.461 & 0.473 & 0.489 & 0.496 & 0.431 \\
\hline & Liaoning & 0.383 & 0.388 & 0.394 & 0.372 & 0.388 & 0.397 & 0.412 & 0.426 & 0.439 & 0.462 & 0.487 & 0.498 & 0.523 & 0.428 \\
\hline & Shanghai & 0.873 & 0.885 & 0.893 & 0.855 & 0.879 & 0.892 & 0.912 & 0.945 & 0.958 & 0.971 & 0.982 & 0.993 & 1.023 & 0.928 \\
\hline & Jiangsu & 0.712 & 0.719 & 0.733 & 0.747 & 0.761 & 0.774 & 0.782 & 0.793 & 0.823 & 0.835 & 0.849 & 0.862 & 0.883 & 0.790 \\
\hline & Zhejiang & 0.773 & 0.776 & 0.783 & 0.761 & 0.783 & 0.799 & 0.812 & 0.825 & 0.836 & 0.856 & 0.869 & 0.876 & 0.897 & 0.819 \\
\hline & Fujian & 0.812 & 0.818 & 0.834 & 0.814 & 0.833 & 0.851 & 0.868 & 0.889 & 0.894 & 0.901 & 0.914 & 0.923 & 0.938 & 0.868 \\
\hline & Shandong & 0.722 & 0.735 & 0.748 & 0.731 & 0.744 & 0.759 & 0.767 & 0.779 & 0.794 & 0.811 & 0.819 & 0.833 & 0.649 & 0.761 \\
\hline & Guangdong & 0.773 & 0.779 & 0.784 & 0.763 & 0.778 & 0.789 & 0.796 & 0.844 & 0.856 & 0.863 & 0.877 & 0.889 & 0.903 & 0.823 \\
\hline & Hainan & 0.773 & 0.785 & 0.796 & 0.791 & 0.813 & 0.824 & 0.831 & 0.843 & 0.859 & 0.862 & 0.877 & 0.881 & 0.896 & 0.833 \\
\hline \multicolumn{2}{|c|}{ Eastern mean } & 0.701 & 0.710 & 0.724 & 0.705 & 0.725 & 0.737 & 0.749 & 0.766 & 0.781 & 0.804 & 0.818 & 0.850 & 0.853 & 0.763 \\
\hline \multirow{8}{*}{ Central } & Shanxi & 0.331 & 0.336 & 0.348 & 0.341 & 0.346 & 0.352 & 0.361 & 0.366 & 0.377 & 0.382 & 0.394 & 0.403 & 0.428 & 0.367 \\
\hline & Jilin & 0.301 & 0.313 & 0.315 & 0.303 & 0.311 & 0.315 & 0.322 & 0.328 & 0.351 & 0.374 & 0.388 & 0.396 & 0.416 & 0.341 \\
\hline & Heilongjiang & 0.523 & 0.526 & 0.535 & 0.529 & 0.536 & 0.549 & 0.558 & 0.568 & 0.578 & 0.583 & 0.592 & 0.599 & 0.611 & 0.561 \\
\hline & Anhui & 0.339 & 0.347 & 0.359 & 0.346 & 0.355 & 0.366 & 0.381 & 0.393 & 0.422 & 0.441 & 0.458 & 0.475 & 0.492 & 0.398 \\
\hline & Jiangxi & 0.342 & 0.345 & 0.351 & 0.361 & 0.373 & 0.384 & 0.395 & 0.407 & 0.418 & 0.429 & 0.441 & 0.458 & 0.472 & 0.398 \\
\hline & Henan & 0.355 & 0.359 & 0.379 & 0.363 & 0.373 & 0.386 & 0.395 & 0.413 & 0.435 & 0.453 & 0.478 & 0.496 & 0.523 & 0.416 \\
\hline & Hubei & 0.533 & 0.539 & 0.548 & 0.541 & 0.553 & 0.563 & 0.579 & 0.588 & 0.598 & 0.601 & 0.616 & 0.629 & 0.641 & 0.579 \\
\hline & Hunan & 0.521 & 0.525 & 0.539 & 0.531 & 0.544 & 0.548 & 0.557 & 0.569 & 0.578 & 0.588 & 0.594 & 0.604 & 0.621 & 0.563 \\
\hline \multicolumn{2}{|c|}{ Central mean } & 0.406 & 0.411 & 0.422 & 0.414 & 0.424 & 0.433 & 0.444 & 0.454 & 0.470 & 0.481 & 0.495 & 0.508 & 0.526 & 0.453 \\
\hline \multirow{11}{*}{ Western } & Neimenggu & 0.287 & 0.292 & 0.299 & 0.285 & 0.301 & 0.317 & 0.328 & 0.339 & 0.354 & 0.376 & 0.392 & 0.411 & 0.433 & 0.340 \\
\hline & Guangxi & 0.332 & 0.338 & 0.349 & 0.346 & 0.358 & 0.365 & 0.374 & 0.394 & 0.403 & 0.411 & 0.423 & 0.459 & 0.477 & 0.387 \\
\hline & Chongqing & 0.543 & 0.549 & 0.553 & 0.562 & 0.549 & 0.547 & 0.539 & 0.537 & 0.541 & 0.533 & 0.529 & 0.528 & 0.511 & 0.540 \\
\hline & Sichuan & 0.302 & 0.311 & 0.328 & 0.312 & 0.319 & 0.329 & 0.338 & 0.339 & 0.343 & 0.347 & 0.351 & 0.359 & 0.362 & 0.334 \\
\hline & Guizhou & 0.223 & 0.227 & 0.236 & 0.231 & 0.239 & 0.248 & 0.255 & 0.273 & 0.298 & 0.311 & 0.325 & 0.337 & 0.356 & 0.274 \\
\hline & Yunnan & 0.319 & 0.324 & 0.335 & 0.329 & 0.341 & 0.349 & 0.361 & 0.384 & 0.399 & 0.412 & 0.423 & 0.438 & 0.449 & 0.374 \\
\hline & Shaanxi & 0.331 & 0.332 & 0.342 & 0.336 & 0.351 & 0.366 & 0.374 & 0.389 & 0.402 & 0.424 & 0.433 & 0.455 & 0.476 & 0.386 \\
\hline & Gansu & 0.298 & 0.312 & 0.327 & 0.319 & 0.343 & 0.356 & 0.368 & 0.379 & 0.388 & 0.399 & 0.423 & 0.437 & 0.463 & 0.370 \\
\hline & Qinghai & 0.568 & 0.578 & 0.584 & 0.571 & 0.573 & 0.581 & 0.592 & 0.603 & 0.614 & 0.633 & 0.657 & 0.673 & 0.688 & 0.609 \\
\hline & Ningxia & 0.504 & 0.517 & 0.544 & 0.531 & 0.539 & 0.544 & 0.561 & 0.578 & 0.588 & 0.593 & 0.603 & 0.632 & 0.644 & 0.568 \\
\hline & Xinjiang & 0.331 & 0.334 & 0.343 & 0.332 & 0.352 & 0.366 & 0.375 & 0.389 & 0.403 & 0.425 & 0.439 & 0.449 & 0.602 & 0.395 \\
\hline \multicolumn{2}{|c|}{ Western mean } & 0.367 & 0.374 & 0.385 & 0.378 & 0.388 & 0.397 & 0.406 & 0.419 & 0.43 & 0.442 & 0.454 & 0.471 & 0.496 & 0.416 \\
\hline \multicolumn{2}{|c|}{ National mean } & 0.500 & 0.507 & 0.519 & 0.508 & 0.521 & 0.531 & 0.542 & 0.556 & 0.569 & 0.585 & 0.598 & 0.62 & 0.635 & 0.553 \\
\hline
\end{tabular}

administrative punishment cases as the measurement indicator of command-control environmental regulation tools. The more cases of administrative punishment, the greater the number of cases of administrative punishment the stricter the standards. The marketencouraging environmental regulation tool is a new type of environmental regulation policy tool, focusing on the market regulation mechanism to fully play its role in environmental protection. At present, it mainly includes the sewage charge system and pollution treatment subsidy system. The current sewage charge system is the most classic environmental regulation tool 
using economic means in China. With reference to the practice of most scholars, the amount of sewage charge is used to represent the market-based environmental regulation tool as PI. At the same time, this article uses the number of environmental pollution letters and visits (EL) to indicate voluntary environmental regulations.

In addition to the environmental regulatory variables selected based on the research needs of this article, in order to more fully explain the factors that affect energy efficiency, this article introduces the following control variables that have a strong impact on energy efficiency:

Technical progress indicator (TE). Technological progress can greatly increase production efficiency, and it is also the source of power for economic growth. According to the analysis above, we can know that environmental regulations will have a significant impact on technological innovation of enterprises. This article chooses the proportion of R \& D expenditures to the GDP.

Industrial Structure (ES). The industrial structure is to analyze the respective proportions of the three major industries in the national economy. Due to the different energy utilization levels in various industries, if the industrial structure changes, the energy efficiency will inevitably change accordingly. In the case of creating the same output in the industrial structure, the consumption of the tertiary industry is much less than the primary and secondary industries. The greater the proportion of the tertiary industry in the industrial structure, the higher the energy efficiency. This article chooses the proportion of the GDP of the secondary and tertiary industries to the regional GDP to measure the industrial structure in China [32].

Energy Consumption Structure (EC). The energy consumption structure refers to the proportional relationship between the various types of energy consumed. The efficiency of different energy types is different. China mainly uses coal consumption. Therefore, the proportion of coal consumption in total energy consumption is used to measure China's energy consumption structure.

Economic Development (ED). The level of economic development in a region will affect the environmental cost of enterprises, the level of technological innovation, and the industrial structure. Therefore, this article selects the level of economic development as the control variable, expressed by GDP per capita, and converted to a constant price based on 2006.

Openness (OP). The impact of the degree of openness on energy efficiency is mainly reflected in the trade structure, that is, the proportion of high energyconsuming products in import and export products will affect the change in energy efficiency of one party [33].

Due to the lack of relevant data in some years in Tibet, based on the availability, continuity and reliability of the data, this article deletes it in the measurement process, and finally selects 30 provinces (autonomous regions) in the western region except
Tibet as the research object, the selected sample period is 2006-2018. The relevant raw data of various policy instrument variables involved in environmental regulation in this article are derived from the 20062018 China Environmental Yearbook and the National Environmental Statistics Bulletin, and the raw data of technological progress and economic development indicators are from 2006-2018. In the China Statistical Yearbook, the missing data of individual years are supplemented by the moving average method, and finally strong panel data is formed.

\section{Regression Results and Analysis Based on System GMM Model}

This article combines existing literature with consideration of the availability of data. It will use command-controlled environmental regulation (LAW), market-encouraged environmental regulation (PI), voluntary environmental regulation (EL), technological progress (TE), and industrial structure. (ES), energy consumption structure (EC), level of economic development (ED), and degree of openness (OP) as explanatory variables and energy efficiency (denoted as EE) as the explanatory variable. The sampling interval is from 2006 to 2018. The regression equation is as follows.

$$
\begin{gathered}
\ln E E=\alpha+\beta_{1} \ln L A W_{i}+\beta_{2} \ln P I_{i}+\beta_{3} \ln E L_{i}+\beta_{4} \ln T E_{i} \\
+\beta_{5} \ln E S_{i}+\beta_{6} \ln E C_{i}+\beta_{7} \ln E D_{i}+\beta_{8} \ln O P_{i}+\mu
\end{gathered}
$$

This paper uses Stata 12.0 software and adopts the system generalized moment estimation method to estimate the model.

Table 3. Regression results.

\begin{tabular}{|c|c|c|c|}
\hline $\begin{array}{c}\text { Explanatory } \\
\text { variable }\end{array}$ & $\begin{array}{c}\text { Parameter } \\
\text { estimate }\end{array}$ & T statistic & P value \\
\hline LnLAW & $-0.0239 * * *$ & -4.832 & 0.0002 \\
\hline LnPI & $0.0153^{* * *}$ & 3.223 & 0.0010 \\
\hline LnEL & -0.0126 & -0.103 & 0.3216 \\
\hline LnTE & $0.0654 * * *$ & 4.083 & 0.0032 \\
\hline LnES & $0.2467 * * *$ & 5.017 & 0.0335 \\
\hline LnEC & $-0.0921 * * *$ & -3.032 & 0.0044 \\
\hline LnED & $0.0231^{* * *}$ & 4.119 & 0.0121 \\
\hline LnOP & $-0.0329 * * *$ & -3.113 & 0.0023 \\
\hline AR(1) & & 0.055 \\
\hline AR(2) & & 0.002 \\
\hline Sargan & \multicolumn{3}{|c}{0.066} \\
\hline Wald & \multicolumn{3}{|c}{0} \\
\hline
\end{tabular}

Note: $* * *, * *, *$ are significant under the conditions of $1 \%$, $5 \%$, and $10 \%$, respectively. 
From the regression results, it can be seen that the number of environmental administrative punishment cases has a negative impact on China's energy efficiency. That is to say, the use of command-andcontrol environmental regulation tools and strong law enforcement has increased the environmental costs of enterprises. It is said that it has a negative effect, which restricts companies to innovate in technology to improve energy efficiency. In contrast to the command-andcontrol environmental regulatory tools, the results of the regression of the market-encouraged environmental regulatory tools on China's energy efficiency show a positive correlation between the two, which means that market-inspired environmental regulatory tools are conducive to achieving environmental regulation and energy efficiency in China.This is same with the opinion of the scholar Wang Xiao (2017), which argues that although the implementation of each environmental regulation tool is costly, compared with the command-controlled environmental regulation tool, the market-based environmental regulation tool can stimulate enterprises more. The subject carries out technological innovation and performance improvement [34]. However, some scholars have reached different conclusions. For example, Fan Yubo (2016) believes that in China, market behavior models and legislative assemblies are affected by the previous system; especially the institutional barriers at the regulatory level have not been completely eliminated. Environmental regulatory tools are still the best choice for controlling pollution and optimizing industrial structure [35]. Studies by foreign scholars Testa and Frey (2011) also found that good command-and-control environmental regulation tools can stimulate enterprises to perform technological innovation more than the other two regulatory tools [36]. This may be due to the different environmental regulation tools adopted by China at different stages, and the different effects of environmental regulation tools on energy efficiency in different periods, so it is of great significance to study the relationship between the two in the new period.

At the same time, it can be seen that the number of environmental pollution letters and visits (EL) instead of voluntary environmental regulation tools has a negative correlation with energy efficiency, but it is not statistically significant. This has some gaps with some scholars' studies. For example, Scholars Li Bin and Chen Chongnuo (2016) also believe that voluntary conscious environmental regulation has a significant promotion effect on energy efficiency, but market incentive environmental regulation has a greater promotion effect on energy efficiency than voluntary conscious environmental regulation [37]. The research in this paper concludes that the greater the number of letters and visits for environmental pollution, indicating that with the progress of society, the public pays more attention to the quality of the environment. Efficiency has a tendency to decline, but it is not the main influencing factor of energy efficiency. It can be seen that this is a different conclusion from previous scholars in the new period.

In addition, other variables have important implications for energy efficiency in China. There is a positive correlation between the level of economic development and technological progress and energy efficiency. A high level of economic development will be transmitted to the impact on energy efficiency through the impact on technology and industry, and promote the improvement of energy efficiency. The improvement of technological level can make full use of resources and create more output with certain inputs; this is consistent with the conclusions of most scholars [38-39]. Among the two indicators of the industrial structure, the proportion of the secondary industry in regional GDP is positively related to energy efficiency. This may be because the Chinese region is a province that depends on coal resources. The secondary industry plays an important role in China's development. It has an irreplaceable status. In the process of actively promoting economic transformation, the improvement of industrial level and process technology are all important reasons for China's secondary industry to promote energy efficiency. There is a negative correlation between the energy consumption structure and energy efficiency represented by the proportion of coal consumption. Coal utilization efficiency is low and pollution is serious, so the higher the proportion, the lower the energy efficiency that includes environmental constraints, this is consistent with the conclusions drawn by most scholars, such as Shi Dan and Zhang Jinlong, Wei Chu and Shen Manhong research shows that different industries have different effects on improving energy efficiency, but overall industrial structure changes can improve energy efficiency [40-41]. The degree of opening to the outside world and the level of government control are negatively related to China's energy efficiency. As a relatively backward economic development region, China has introduced advanced technologies in the process of opening to the outside world, but it has also reduced environmental regulations in order to attract investment and attract investment. The standard has made China a pollution haven in economically developed regions, and the increase in high-energyconsuming industries has restricted the improvement of energy efficiency in China. This is different from the research results of some scholars. For example, Li Weiwu [42] explored the general mechanism of the impact of opening up on energy efficiency from a theoretical perspective. The results show that opening up has a positive effect on improving energy efficiency. This may be due to the different policies for foreign investment in different regions of China, which in turn produce different results.The higher the degree of government intervention in economic development, the more it is not conducive to the realization of marketization and the optimal allocation of resources. Resource waste restricts the improvement of energy efficiency. 


\section{Conclusions}

This paper uses super-efficiency data envelope analysis and systematic GMM model analysis to study the super-efficiency energy efficiency values, energy efficiency changes, and the impact of different environmental regulatory tools on energy efficiency in 30 provinces in China from 2006 to 2018. Conclusion as follows:

From 2006 to 2018, China's inter-provincial energy efficiency values have generally improved, indicating that more and more attention has been paid to improving energy efficiency, but the overall level of efficiency is still relatively low, and there is still much room for improvement. According to the energy efficiency evaluation of Chinese provinces in the past 13 years, it can be seen that the regions from high to low energy efficiency are in turn the eastern region, the central region, and the western region. The energy efficiency of the eastern region has shown a significant upward trend, but the increase has declined in recent years, mainly due to the improvement of energy efficiency across the country, leading to the overall movement of the energy efficiency frontier, and the increase in energy efficiency in the eastern region has decreased; Regional energy efficiency has always been relatively stable, showing a slight upward trend. Energy efficiency in the western region has always been lower than the national average, but it has been slowly increasing. Due to the backward economy in the western region, the energy efficiency of most provinces is concentrated in the western region, and energy efficiency in eight regions is less than 0.4. It can be seen that the key area for energy efficiency improvement is the western region with a relatively backward economy.

From the perspective of the impact of different environmental regulation tools on energy efficiency, the number of environmental administrative punishment cases has a negative impact on China's energy efficiency, which has a negative effect on enterprises in China; market-encouraged environmental regulation tools have The results of the regression of the impact of China's energy efficiency show a positive correlation between the two, which means that market-inspired environmental regulation tools are conducive to achieving the win-win purpose of environmental regulation and energy efficiency improvement in China. The number of environmental pollution letters and letters from voluntary environmental regulation tools has a negative correlation with energy efficiency, but it is not statistically significant, indicating that it is not the main factor affecting energy efficiency. In terms of other influencing variables, the level of economic development and technological progress are positively related to energy efficiency. The proportion of the secondary industry in regional GDP is positively related to energy efficiency, and the relationship between energy consumption structure and energy efficiency is negative. Correlation, the degree of opening to the outside world has a negative correlation to China's energy efficiency.

From the above analysis, we can know that the impact of different environmental regulation tools on China's energy efficiency is different. In the future, while focusing on the intensity of environmental regulations, we must also use environmental regulation tools. Compared to command-and-control environmental regulation tools, China is obviously Regional market-inspired regulatory tools are more effective in promoting China's energy efficiency, so we must pay attention to the use of market-encouraged environmental regulatory tools. In addition, although the impact of voluntary environmental regulation on China's energy efficiency is not significant, in recent years, as the public's awareness of environmental protection has continued to increase, such environmental regulation tools have developed rapidly, and they cannot be ignored.

\section{Acknowledgements}

This article is a funded project for the outstanding young backbone teachers of the 'Blue Project' in the Department of Education, Jiangsu Province, 2019.

\section{Conflict of Interest}

The authors declare no conflict of interest.

\section{References}

1. WU J., TAN T., YANG H. Research on Total Factor Energy Efficiency Evaluation in China - Based on an Indivisible Three-Phase DEA Model. Mathematical Statistics and Management, 3, 418, 2019.

2. YUE L., YANG Y.C. Spatio-temporal differentiation of green total factor energy efficiency in countries along the "Belt and Road"-based on super-efficiency DEA model and GML index method. Exploration of Economic Issues, 6, 111, 2019.

3. DONG F., LI J., LI K., SUN Z., YU B., WANG Y., ZHANG S. Causal chain of haze decoupling efforts and its action mechanism: Evidence from 30 provinces in China. Journal of Cleaner Production, 118889, 2019.

4. DONG F., WANG Y., ZHENG L., LI J., XIE S. Can industrial agglomeration promote pollution agglomeration? Evidence from China. Journal of Cleaner Production, 118960, 2019.

5. DONG F., ZHANG S., LONG R., ZHANG, X., SUN Z. Determinants of haze pollution: An analysis from the perspective of spatiotemporal heterogeneity. Journal of Cleaner Production, 222, 768, 2019a.

6. ZENG S.L., ZHANG Y.M., DENG X. Research Progress and Prospects of Industrial Total Factor Energy Efficiency. Eco-Economy, 11, 25, 2018.

7. PORTER M.E. America's Green Strategy. Scientific American, 264 (4), 132, 1991. 
8. JEAN L.R., EVAN W.L., ANDREW S. Environmental quality and the cost of environmental regulation: A comparison of Scotland with the international community. Environmental Policy \& Governance, 18 (1), 45, 2008.

9. YANG Z.J., ZHU G.L. Technological Innovation, Environmental Regulation and Energy Efficiency Empirical Test Based on Chinese Provincial Panel Data. Research and Development Management, 4, 23, 2017.

10. JORGENSON D.W., WILCOXEN P.J. Fundamental U.S. Tax Reform and Energy Markets. Energy Journal, 18 (3), 1, 1997.

11. LI W.N., JIN X.Y. Research on Environmental Technology Efficiency of Chinese Manufacturing Industry. China Science and Technology Forum, 2, 35, 2011.

12. YOU J.H., GAO Z.G. Empirical Study on the Impact of Government Environmental Regulations on Energy Efficiency - Taking Xinjiang as an Example. Resources Science, 6, 99, 2013.

13. CHEN L., ZHAO G.C. Impact of Local Government Environmental Regulations on Total Factor Energy Efficiency: An Empirical Study Based on Xinjiang Panel Data. Arid Land Resources and Environment, 8, 10, 2014.

14. WAN L.L., TONG M.Y. Analysis of the Influencing Factors of China's Energy Intensity under Environmental Regulations - An Empirical Study Based on Interprovincial Panel Data. Journal of Shanxi University of Finance and Economics, s2, 6, 2010.

15. LI B., CHEN C.N. Empirical test of the impact of heterogeneous environmental regulations on China's industrial energy efficiency. Statistics and Decision, 3, 129, 2016.

16. FAN M.Q. Impact of environmental regulation on total factor energy efficiency .Dongbei University of Finance and Economics, 2015.

17. BAI X.J, SONG Y. Environmental regulation, technological innovation and efficiency improvement of China's thermal power industry. China Industrial Economy, 8, 70, 2009.

18. PORTER M.E., VANDER L. Green and competitive: ending the stalemate. Harvard Business Review, 73 (5), $120,1995$.

19. GAO S. Study on the impact of environmental regulations on energy efficiency in high energy-consuming industries. Jinan University, 2012.

20. GAO Z.G., YOU J.H. Study on the intensity of environmental regulation and China's total factor energy efficiency. Comparison of Economic and Social Systems, 6, 111, 2015.

21. CHEN D.M., ZHANG R. The Impact of Environmental Regulations on China's Total Factor Energy Efficiency: An Empirical Test Based on Provincial Panel Data. Economic Sciences, 34 (4), 49, 2012.

22. WANG T., YAN L., HE J.H. Empirical study on the impact of environmental regulations on total factor energy efficiency: a decomposition verification based on the Porter hypothesis. China Environmental Science, 4, 373, 2017.

23. XIONG H.H., DENG W.T. An Empirical Analysis of the Relationship between Environmental Regulation, Industrial Agglomeration and Energy Efficiency. Statistics and Decision, 21, 121, 2017.
24. ROGGE N., JAEGER S.D. Measuring and explaining the cost efficiency of municipal solid waste collection and processing services. Omega, 41 (4), 653, 2013.

25. BLANCARD S., MARTIN E. Energy efficiency measurement in agriculture with imprecise energy content information. Energy Policy, 66, 198, 2014.

26. LIN B., LONG H. A stochastic frontier analysis of energy efficiency of China 's chemical industry. Journal of CleanerProduction, 87 (1), 235, 2015.

27. ANDERSEN P., PETERSEN N.C. A Procedure for Ranking Efficient Units in Data Envelopment Analysis. INFORMS, 1993.

28. ZHANG J. Analysis of Urban Ecosystem Efficiency Based on Emergy Method and DEA Model - Taking Beijing as an Example. Industry and Science Forum, 19, 94, 2017.

29. ALMALKAWI A.T., SOROUSHIAN P., SHRESTHA S.S. Evaluation of the Energy-Efficiency of an Aerated SlurryInfiltrated Mesh Building System with Biomass-Based Insulation. Renewable energy, 133, 797, 2019.

30. CHEN J.J., Chambers D. Sustainability and the impact of Chinese policy initiatives upon construction[J]. Construction Management \& Economics, 17 (5), 679, 1999.

31. WILSON B., TRIEU L.H. Bowen B. Energy Efficiency Trends in Australia. Energy Policy, 22 (4), 287, 1994.

32. VALERIA C., FRANCESCO C. Environmental regulation and the export dynamics of energy technologies. Ecological Economics, 66 (2-3), 447, 2008.

33. TABREZ A. Environmental Regulation of Energy Sector in India. Ssrn Electronic Journal, 1, 689, 2014.

34. WANG X. Analysis of the impact of different environmental regulatory tools on corporate performance. Nanchang University of Aeronautics, 2017.

35. FAN Y.B. Industrial Structure Effect of Environmental Regulation: History, Logic and Empirical. Shandong University, 2016.

36. Testa Iraldo \& Frey. The effect of environmental regulation on firms' competitive performance. Journal of environment management, 92, 2136, 2011.

37. LI B., CHEN C.N. Empirical Test on the Impact of Heterogeneous Environmental Regulations on Energy Efficiency of Chinese Industries. Statistics and Decision, 3, 129, 2016.

38. CROMPTON P., WU Y.R. Energy consumption in China: past trends and future directions. Energy Economics, 27, 195, 2005.

39. FISHER-VANDEN K. What is driving China's decline in energy intensity? Resource and Energy Economics, 26, 77, 2004.

40. SHI D., ZHANG J.L. Impact of industrial structure change on energy consumption. Economic Theory and Economic Management, 8, 30, 2003.

41. WEI C., SHEN M.H. Energy Efficiency and Its Influencing Factors: An Empirical Analysis Based on DEA. Management World, 8, 66, 2007.

42. LI W.W. Opening to the Outside World and Energy Efficiency: An Empirical Study Based on 35 Industrial Industries.International Trade Issues, 6, 7, 2008. 